\title{
Effect of Cooling velocity on Microstructure and Mechanical Properties
}

\author{
Zhiyi Zhang ${ }^{1, a}$, Yongshou $\mathrm{Wu}^{1, \mathrm{~b}}$, Chao Zhou ${ }^{1, \mathrm{c}}$ \\ ${ }^{1}$ CSR SIFANG Co., Ltd, Qingdao 266111, P.R China \\ a yefan_0954@163.com, buyongshou2003@163.com, ${ }^{\mathrm{c}} 103598879 @ q q . c o m$
}

Keywords: SHCCT; phase transformation; cooling rate;

Abstract. The SHCCT diagram is a curve that can reflect the start point, the end of the phase transformation, which is significant in optimizing welding parameters and making a reasonable process parameters. In this paper, the weathering steel S355J2W at different cooling rate was employed to simulated the heating effecting zone. Microstructure was observed and hardness were tested to investigate effect of cooling rate on microstructure and hardness. The results showed that the austenite transformed into ferrite 、 pearlite and bainite instead of ferrite and pearlite phases with the cooling rate increased from $0.05^{\circ} \mathrm{C} / \mathrm{s}$ to $100^{\circ} \mathrm{C} / \mathrm{s}$. The pearlite phase disappeared completely when the the cooling rate was $2^{\circ} \mathrm{C} / \mathrm{s}$. The microstructure was completely composed of bainite when the cooling rate was $3^{\circ} \mathrm{C} / \mathrm{s}$. When the cooling rate reached $10^{\circ} \mathrm{C} / \mathrm{s}$, martensite phases appeared which could be identified from the picture of the microstructure. The hardness increased with the increase of cooling rate due to different phase composition.

\section{Introduction}

With the development of "B\&R Initiative" and the high-speed rail "going out" strategy, fast and heavy rail traffic is of great significance for its natural advantages of all-weather. Reinforcement of high strengthen weathering steel means lightweight, low-cost, low-energy for the field of railway vehicles, containers and so on, which is an important development direction. Typical Q345C, S355J2W (H) and SMA490BW made in Japan are employed in the high-speed train bogies manufacturing ${ }^{[1 \sim 4]}$.

Solid phase metallurgy of steel in welding process is different from solid phase transformation in heat treatment. Continuous cooling transformation curve by heat treatment can not be simply employed to research the problem of welding metallurgy ${ }^{[5 \sim 7]}$. Under the influence of welding heat cycle, uneven distribution of microstructure and properties of HAZ results in weak parts of the welded joints. The problems of hardening, cold cracking, local brittle and reheat cracks generated in HAZ are related to structure change and transformation products in weld cooling conditions.

This paper aims at the microstructure and hardness at different cooling rates of high-speed train bogie material S355J2W $(\mathrm{H})$. Influence of cooling velocity on the microstructure and hardness are investigated, which is used to assess its weldability, select appropriate welding parameters and develop a reasonable welding process.

\section{Experimental Materials and Methods}

\section{Experimental Materials}

The material used in this paper was $12 \mathrm{~mm}$ thick weathering steel S355J2W $(\mathrm{H})$. The chemical composition was shown in Table 1.

Table 1 chemical composition of S355J2W

\begin{tabular}{|l|l|l|l|l|l|l|l|l|l|l|l|l|}
\hline trademark & $\mathrm{C}$ & $\mathrm{Si}$ & $\mathrm{Mn}$ & $\mathrm{P}$ & $\mathrm{S}$ & $\mathrm{Cu}$ & $\mathrm{Ni}$ & $\mathrm{Cr}$ & $\mathrm{V}$ & $\mathrm{Nb}$ & $\mathrm{Al}$ & $\mathrm{Ti}$ \\
\hline $\mathrm{S} 355 \mathrm{~J} 2 \mathrm{~W}(\mathrm{H})$ & 0.07 & 0.276 & 1.288 & 0.009 & 0.001 & 0.269 & 0.17 & 0.477 & 0.035 & 0.013 & 0.012 & 0.009 \\
\hline
\end{tabular}

\section{Experimental process}

(1) Preparation of MAG welded joint. The heating rate of temperature cycling, the peak temperature, holding time of heat-affected zone was measured to access to the welding heat cycle curve.

(2) The sample was cleaned in ultrasonic cleaning. Vernier caliper to employed to find the midpoint of the sample and well marked. The sample size is $\Phi 6 \times 90 \mathrm{~mm}$. Then, the prepared one pair of 
K-type thermocouple was spot-welded to the midpoint of the sample. Finally, the specimen ends welded thermocouple is mounted on the copper jig. The distance between the two clamps can be adjusted depending on the cooling rate.

(3) The heating rate, peak temperature and holding time obtained by the thermal cycle curve were input to the thermal simulation testing program. The data of the sample cooling from the peak temperature to $800{ }^{\circ} \mathrm{C}$ was in accordance to the thermal cycle test results. And then the samples were cooled from $800^{\circ} \mathrm{C}$ to $500^{\circ} \mathrm{C}$ at different cooling rate. During cooling, the sample undergone phase change. The phase transition temperature at different cooling rate was determined from the turning point in the thermal expansion curve.

(4) A1M optical microscope was employed to observe HAZ metallographic at different cooling rate conditions. Ten field shooting were chosen to calculate the proportion of each phase by using Image Pro Plus software. Scanning Electron Microscope (SEM) was used to analyze the microstructure

(5) The hardness of the heat affected zone under different cooling rates conditions by using HVS-30 Vickers. The test load was $5 \mathrm{~kg}$, dwelling time of $10 \mathrm{~s}$. The hardness of each sample was averaged by 5 points.

\section{Results and discussion}

\section{Microstructure Analysis}
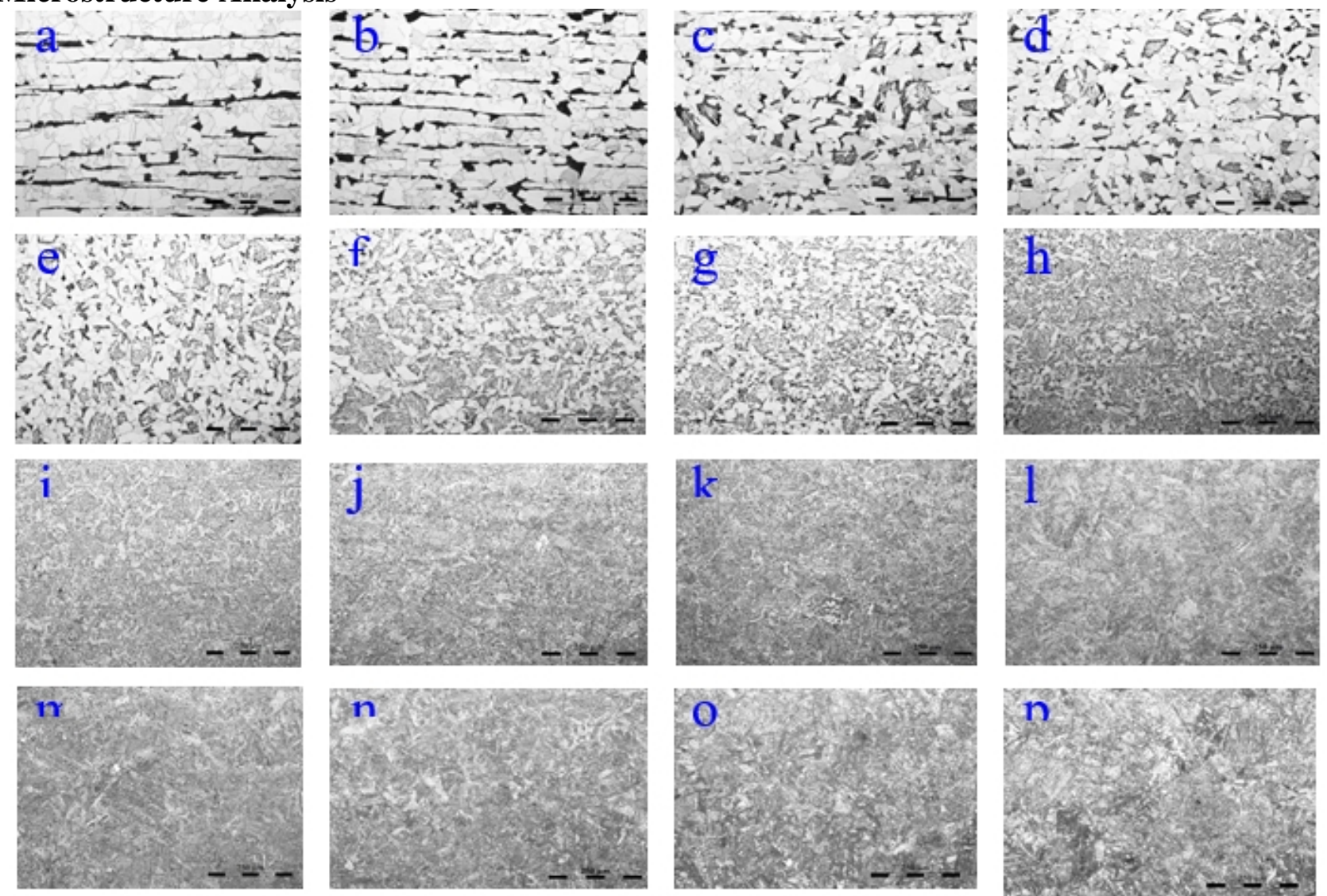

Fig. 1 Microstructure of S355J2W steel in different cool velocity: (a) $0.05^{\circ} \mathrm{C} / \mathrm{s} ;(\mathrm{b}) 0.1^{\circ} \mathrm{C} / \mathrm{s} ;(\mathrm{c}) 0.2^{\circ} \mathrm{C}$

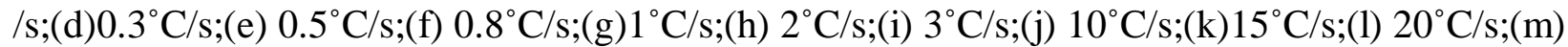
$30^{\circ} \mathrm{C} / \mathrm{s} ;(\mathrm{n}) 40^{\circ} \mathrm{C} / \mathrm{s} ;(\mathrm{o}) 60^{\circ} \mathrm{C} / \mathrm{s} ;$ (p) $100^{\circ} \mathrm{C} / \mathrm{s}$;

Fig. 1 showed the metallurgical microstructure of S355J2W steel at different cooling rates. It can be seen from Fig.1 (a) and (b) that the microstructure of heat-affected zone of S355J2W steel at a cooling rate of $0.05^{\circ} \mathrm{C} / \mathrm{s}$ and $0.1^{\circ} \mathrm{C} / \mathrm{s}$ was bulk ferrite and stripped pearlite. The stripped structure was the two kinds of tissue along the hot deformation direction, almost parallel, showing an alternate 
arrangement of stripped structure. When cooling rate was in the range of $0.2^{\circ} \mathrm{C} / \mathrm{s} \sim 1{ }^{\circ} \mathrm{C} / \mathrm{s}$, the structure was composed of ferrite, pearlite and bainite, as shown in Fig.1(d)-(g). When the cooling rate reached $2^{\circ} \mathrm{C} / \mathrm{s}$, the transformation of pearlite was inhabited, obtaining ferrite and bainite, as shown in Fig.1(h). With the increasing of cooling rate to $3^{\circ} \mathrm{C} / \mathrm{s} \sim 10^{\circ} \mathrm{C} / \mathrm{s}$, the structure was completely composed of bainite, as shown in Fig.1(i) and (j). When the cooling rate was greater than $15^{\circ} \mathrm{C} / \mathrm{s}$, martensite appeared, as shown in Fig.1(k)-(q).

\section{SEM observation organization}
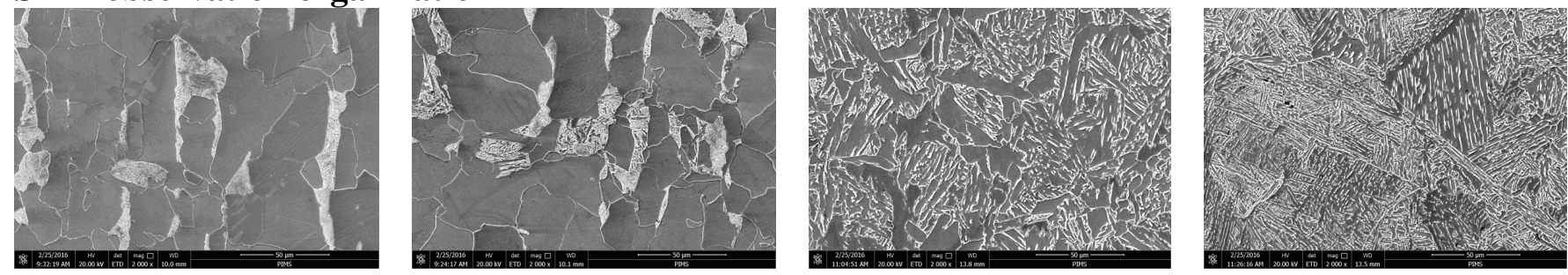

Fig. 2 SEM image of HAZ at different cooling velocity: (a) $0.1^{\circ} \mathrm{C} / \mathrm{s} ;(\mathrm{b}) 0.2^{\circ} \mathrm{C} / \mathrm{s} ;(\mathrm{c}) 3^{\circ} \mathrm{C} / \mathrm{s} ;(\mathrm{d}) 20^{\circ} \mathrm{C} / \mathrm{s}$

In order to analyze the microstructure of each group under the cooling rate of the sample more clearly, SEM was employed to observe the microstructure, as shown in Fig.2. Fig.2(c) showed typical structure of bainite. In bainite transformation region, ferrite lath inside the crystal was thick and short, the distance was large. With the increasing of cooling rate, bainitic ferrite prime body strip became fine, ferrite sheet body length increase, reduce the width and phase distance getting smaller. The strip has obvious traces of the original austenite grain boundary grown to crystal inside. The carbide tranformed from rod to granular. This can be seen clearly seen from Fig.2(c) and (d). When the cooling rate increased to $20^{\circ} \mathrm{C} / \mathrm{s}$, it is mixed microstructure of bainite and martensite. In the area of martensite transformation, the martensite lath also narrowing and thinning with the increase of cooling rate.

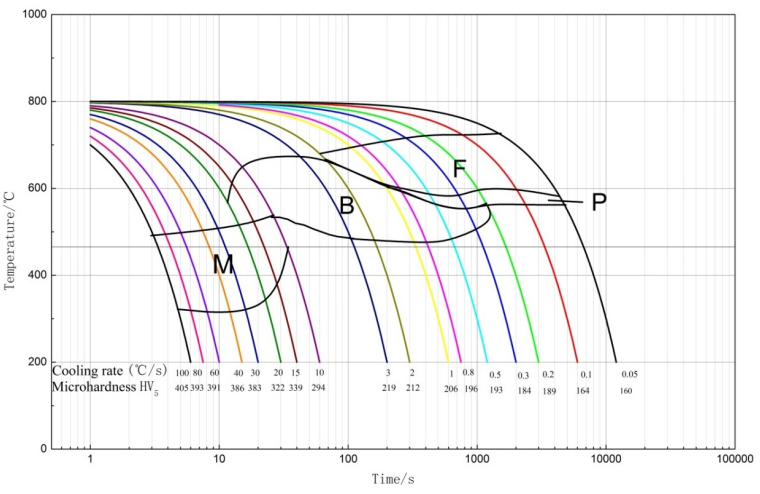

Fig.3 SHCCT curve of S355J2W steel

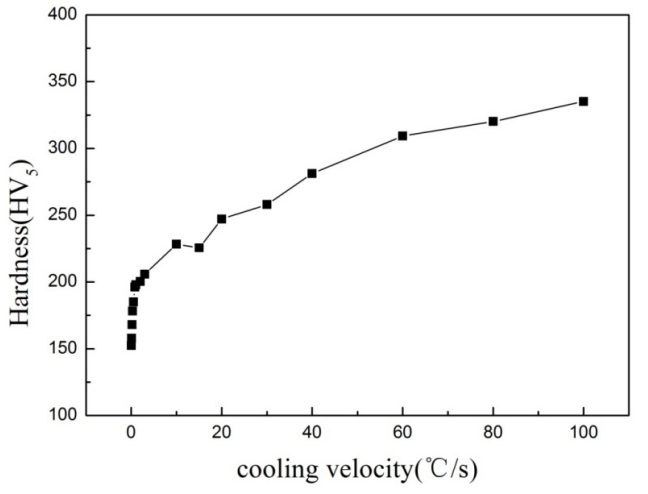

Figure 4 curve hardness and cooling rate

Fig. 3 showed SHCCT curve of S355J2W steel. The curve can be divided into 3 regions. When the cooling rate was in the range of $0.05 \sim 1{ }^{\circ} \mathrm{C} / \mathrm{s}$, the structure was composed of ferrite, pearlite and bainite. Thus when the cooling curve mobiled from the left-up side to the right-down side, first intersect with the ferrite transformation beginning line, which began to precipitation of ferrite. With the temperature decreased to intersect with pearlite transformation starting line (i.e., the precipitation of proeutectoid ferrite terminated lines), which happened austenite to pearlite transformation. With the temperature continues to decline, intersect with bainite transformation beginning line, which indicated that austenite transforemed to pearlite. Finally ferrite, pearlite and bainite were obtained.

When the cooling rate was in the range of $1 \sim 2^{\circ} \mathrm{C} / \mathrm{s}$, the cooling rate increased. Thus when the cooling curve mobiled from the left-up side to the right-down side, first intersect with the ferrite transformation beginning line. With the temperature decreased to intersect with bainite transformation starting line, which happened austenite to pearlite transformation. And then the curve intersect with bainite transformation end line, which meant that transformation of supercooled austenite to bainite completed.

Cooling rate reaches 2 to $10{ }^{\circ} \mathrm{C} / \mathrm{s}$, along with decreasing temperature, cooling curve first entered the bainite transformation region, forming bainite and residual austenite. As the temperature continues 
to decrease, crossing martensitic transformation lines. At this time retained austenite transformed to martensite, obtaining integration structure of bainite and martensite. Further increasing the cooling rate, the degree of cooling and phase transformation driving force increased, which decreased the transition temperature and shortened the time begin to change the start. The diffusion ability of $\mathrm{Fe}$ and $\mathrm{C}$ atoms was very low, which resulted in impossiblility of austenite divided into $\alpha$ and $\mathrm{Fe} 3 \mathrm{C}$ phase, only forming the the same phase composition as $\gamma$ phase (named as $\alpha^{\prime}$ phase). The carbon concentration far exceeded the balance solubility of $\alpha$ phase, which occurs only martensite transformation. The cooling rate curve first meets the martensitic transformation line (Ms line), which began the transformation of austenite to martensite, and finally obtained the martensite and retained austenite.

The relationship between the hardness and the cooling rate was shown in Fig.4. The hardness of the sample increased with the increasing of the cooling rate. This was because that at the condition of continuous cooling, carbon existed in austenite had no time to diffuse and aggregate at high temperature, thus exist in the form of saturation in the original austenite and subsequently transformation occurred in the low-temperature range. The phase transition products was mainly bainite. Bainite was not only rich in carbon, but also contained a large number of lattice defects compared with ferrite. Therefore along with the cooling rate and the increase of the content of bainite, the hardness of heat affected zone gradually increased. According to the SHCCT curve, with the increase of cooling rate, four types of structure change of $\mathrm{B}+\mathrm{F}, \mathrm{P}+\mathrm{F}+\mathrm{B}, \mathrm{B}+\mathrm{M}$ and $\mathrm{P}+\mathrm{F}$ were occurred in the simulated heat affected zone.

\section{Conclusions}

(1)Austenite transformed into ferrite , pearlite and bainite instead of ferrite and pearlite phases with the cooling rate increased from $0.05^{\circ} \mathrm{C} / \mathrm{s}$ to $100^{\circ} \mathrm{C} / \mathrm{s}$. The pearlite phase disappeared completely when the the cooling rate was $2^{\circ} \mathrm{C} / \mathrm{s}$. The microstructure was completely composed of bainite when the cooling rate was $3^{\circ} \mathrm{C} / \mathrm{s}$. When the cooling rate reached $10^{\circ} \mathrm{C} / \mathrm{s}$, martensite phases appeared which could be identified from the picture of the microstructure.

(2)The hardness increased with the increase of cooling rate due to different phase composition.

\section{References}

[1] Feng Hui.Effects of $\mathrm{Cu}, \mathrm{Cr}$ and $\mathrm{P}$ on Weathering Steel of 355MPa Grade[D].NORTHEASTERN UNIVERSITY.2010:1-12.

[2] Hao Xinfeng. Development of the Atmospheric Corrosion Protection of Weathering Steel [J], Shonghai Steel \& Iron Research,2001,2:34-39.

[3] Li Fei,Fu Maohai. Research on Development and Operation of High Speed Passenger Car Bogies [J]. ROLLING STOCK,2004(10):1-7.

[4] Ding Wei,Liu Xuewen,Huang Chenkui, Zhang Xiaojun. Study and Analysis on Material Capability for High-speed Welding Bogies [J]. ZGTK,2001(2):71-75.

[5] YU Yangchun, XIE Ming-li, LI Zhiyuan. Effect of secondary thermal cycle on intragranular ferrite[J].TRANSACTIONS OF THE CHINA WELDING INSTITUTION.2013(2): p89 92,96

[6] HAN Huanxiao, WANG Yong, LV Tongquan. Micro-structure Brittleness of Heat Affected Zone after the Second Thermal Cycle for X 80 Pipeline Steel [J].CPVT,2008(2):9-12. 
[7] Zhou Zhiliang. Microstructure and Toughness Properties of Simulated MultipassWeld Metals in a TMCP Steel [J]. JOURNAL OF DALIAN RAILWAY INSTITUTE,19998(19):69-73.

[8] A.ghosh, S.Das, S.Chatterjee, P.Ramachandra Rao.Effct of Cooling Rate on Structure and Properties of an Ultra-Low Carbon HSLA-100 Grade Steel.[J]Materials Characterization 56(2006):59-65.

[9] Cui Zhanquan, Kang Guowang, Zhang Xianghong, Zhai Jinpo,Cao Guoyang,Wang Hongming, Sun Xiaoguang Measuration and Analysis of SHCCT Curve for 3Cr-1Mo-0.25V Steel[J]. Physics Examination and Testing 2008(1):1-5

[10] Li Hongying.Determination and Application of CCT Diagram for 6082 Aluminum Alloy[J].ACTA METALLURGICA SINICA.2010(10):1237-1243. 